\title{
Literary Facebook Narratology: Experientiality, Simultaneity, Tellability ${ }^{1}$
}

\author{
Maria Mäkelä \\ Tampere University
}

nothing else but what happens to me, such as speaking

(Beckett, The Unnamable, 360)

In the contemporary field of narrative theory, which combines literary and socialscience approaches, the socio-cultural aspects of social-media storytelling have been widely discussed. However, the literary potential of social-media storytelling has gone almost unnoticed. We need research on the literary craft in social media and on its interpretation, as platforms such as Facebook or Twitter are gradually transforming our understanding of what is meant by narrative and what narrative is considered compelling (Georgakopoulou 2013: 220-21 and 2017: 36-38). From the perspective of literary narratology, the two-way traffic between conventions of literary fiction and conventions of social-media storytelling should be of key interest, but little research exists on the topic thus far. Narratologists have, for example, considered the insertion of web-based material within novels (e.g. Hallett 2014) and the borrowing of literary techniques and attempts at literary creativity in Twitterfiction (Thomas 2013 and 2016). Yet more traditionally "narratological" text-oriented questions such as the parallels between simultaneous narration in the novel and on-line social media experientiality, have received scant attention. Transmedial narratology is more interested in how storyworld franchises travel

\footnotetext{
${ }^{1}$ This article was written during a research period in my postdoctoral project "Voice as Experience: Life-Storying in Contemporary Media" (2014-2018, no. 276656), funded by the Academy of Finland.
} 
from one medium to another (e.g. Thon 2016) than in the interaction of narrative techniques and interpretative frames between media.

Notable exceptions within the paradigm are studies by Ruth Page and Alexandra Georgakopoulou. Page has brought together literature-based narratology and sociolinguistics in order to analyze language, narrativity, identities, and interactivity in online storytelling (see, esp., 2010, 2012, 2015; Page, Harper, and Frobenius). Georgakopoulou has directed narrative scholarship's attention to the "miniaturization" of contemporary storytelling practices shaped by the affordances ${ }^{2}$ of social media, as well as by the tendency to focus on "breaking news" (simultaneous and fragmentary narration especially in mediated interaction) instead of sorting out temporal-causal relations (e.g. 2007, 2013, 2017). Georgakopouolou grounds parts of her argument on work done in cognitive narratology $(2013,208-$ 212). But what seems to be missing is a narrative-theoretically informed reading of the creative potential in verbalizing one's thoughts and impressions and interpreting the updates by others on social media. In this article, I present a qualitative analysis of select of Facebook status updates by academic friends in order to demonstrate what a pronouncedly literary-narratological analysis of social media storytelling might look like. This "literalization" requires the setting aside of some affordances of the medium while - more or less "unnaturally" - foregrounding others.

In order to focus on the particularly literary potential of Facebook, I will confine my analysis to textual self-storying and its platform-specific possibilities and limitations only with respect to the original status update by an individual, disregarding both the multimedial constellations of word, sound, and image and the interactive elements of liking, sharing, and commenting which have been studied extensively by Page and others.

As compensation for this limitation, I propose a new function for narratology within the study of social media, based on a seemingly simple hypothesis: it is possible to perform a literary-narratological analysis of non-literary material by adopting a sophisticated reading strategy when dealing with allegedly unsophisticated material. A second claim is that this literary reading strategy vis-àvis Facebook status updates is not only a methodological stance adapted by a

2 By 'affordance' I refer to the formal potential and constraints of a specific medium or text type (see, e.g. Levine 2015, Contzen 2018). 
literary scholar but forms an elementary part of the enjoyment that social media users derive from online storytelling. The latter hypothesis relates to my earlier work within the paradigm of unnatural narratology.

Contrary to the majority of contributions in this emerging paradigm, my own studies have not been on the lookout for specific kinds of "unnatural narratives" but have tried to demonstrate that even the most mundane reading experience has its "unnatural" tendencies. These include a heightened attention to medium-specific facets such as textuality and composition, aspects of storytelling that risk being neglected if we uncritically accept the universality claims promoted by the dominant cognitive-theoretical notions of narrative sense-making (see esp. Mäkelä 2013a, 2013b, 2016; Mäkelä and Polvinen 2018). It is from these arguments that I derive my notion of the "literary" also for the purposes of the study at hand: literariness, when exported outside literary genres, is a reading strategy characterized by a heightened attentiveness to the creativity of form, ambiguity, and the exchange between intentional artistry and accidental aesthetics.

Thus my aim is not to consider everyday posts in Facebook as art forms per se but rather to test what an aestheticizing point of view might tell us about the narrative and expressive potential of this specific platform. I find support for my strongest methodological preference - the foregrounding of the verbal component in Facebook narration - from Werner Wolf, one of the most eminent scholars of intermedial narratology. Wolf maintains that a genuinely productive and sustainable application of literary narratology to non-literary material can only concern the analysis of textual techniques and can only be achieved by continuously acknowledging the literary origins of the discipline (159). I follow these principles in my analysis by concentrating on the creative ways in which a social media updater or reader can explore the relationship between textual self-expression and narrativity, as well as by seeking to understand some of the rhetorical and interpretive effects of social media that can be aligned with the literary conventions of the modern novel, and especially those of consciousness representation and the interpretative and temporal tensions between the reporting voice and the experiencing voice - theoretical questions that I have addressed in my previous work.

In spite of this method of artificial foregrounding and rejection of cognitive universality as a starting point, the key concepts of my analysis - experientiality, 
simultaneity, and tellability - derive from the contemporary interdisciplinary field of narrative theory and are thus readily applicable to all kinds of storytelling. I will deal with these concepts and their transdisciplinary potential below, recontextualizing and instrumentalizing them in order to promote what I call "literary Facebook narratology." In addition, I will consider the method and the materials in the context of "small stories" research initiated by Michael Bamberg and Alexandra Georgakopoulou (2008). My small demo analyses provide a freshly literary-aestheticizing approach to questions of experientiality, tellability, and simultaneity in social media narration, aspects formerly tackled by sociologists and sociolinguists. The emphasis will be laid on life-storying, posts that concentrate on the personal, daily life of the updater.

Thus, my contribution is first and foremost a narrative-theoretical and methodological approach to the creative and expressive potential of Facebook as a culturally dominant platform for self-expression and life-writing, whose forms and functions create repercussions in other narrative environments, in contemporary fiction as well as in face-to-face communication. By framing analytical concepts partly derived from the social-science study of storytelling with aestheticizing discourses adapted from literary studies, we may begin to appreciate the expressive potential of short-form on-line narrative platforms. My aim is to show (1) how experientiality, simultaneity, and tellability are crucial building blocks in textual Facebook narrativity and its interpretation, (2) how they define the verbal limits and affordances of the medium, and (3) how the verbal craft of Facebook status updates results, to a large extent, from the manipulation of these three facets. In spirit, this approach resembles Clement Greenberg's (1940) famous "medium-specific" notion of (Modernist) art as the exploration of the limits of its own medium (see also Toikkanen in this special issue), although I am at the same time both limiting my analysis to textual narration and advocating transdisciplinary reading strategies. Admittedly, this approach will result in a more or less "Modernist" reading of Facebook, but this emphasis too is in line with the literary-narratological tradition: formalist readings, especially of Modernist writers such as Proust, Joyce, and Hemingway, form an important part of the foundation of narratology as a discipline.

A cautionary word on my miniature corpus is needed. The analysed Facebook status updates were written by early middle-aged (30-50) users, all trained either in linguistics or in literary theory or both, so one could suspect them 
of being more self-aware of their textual strategies than an average user. Most of my Facebook friends and I represent a generation that, as of now, continues to be excited about the expressive - especially verbal — potential of this platform, while younger generations have already moved into new applications and new, often increasingly visual, forms of social media existence (see, e.g. Cinque 2015). I have chosen the examples somewhat at random, but also because of their representativeness - a symptomatic logic of selection for a literary scholar. My analyses provide a case study on how experience and its narrative interpretation may take shape in social media, and how these procedures relate to literary understanding. I have secured consent from these selected Facebook friends to use their updates in research contexts.

\section{Experientiality}

The concept of experientiality encapsulates one of the eminent paradigm shifts within narratology and is a cornerstone of postclassical narratology: Monika Fludernik's redefinition of narrativity as "mediated experientiality" (12-13, 28-30), as opposed to structuralist definitions rooted in temporality and causality, has, by now, been widely accepted in narrative studies. Fludernik's natural narratology forcefully promotes the cognitive-narratological universality thesis. The primary impulse of the reader construct erected by cognitive narratology is always that of reduction: in narrative meaning-making, markers and effects of artificiality or medium-specificity are set aside by "naturalizing” (cf. Culler 138) or "narrativizing" (Fludernik 33) any kind of (even only remotely narrative-like) representation to fit our basic cognitive schemata for story comprehension. The quest for experientiality in representations works the same way: the reader is on the lookout for familiar epistemic, affective, and bodily parameters that would yield a presentation akin to the reader's experiential schemata. One of Fludernik's major contributions was to bring social linguistics into dialogue with literary narratology by arguing that the universal groundwork for narrative comprehension is laid in "naturally occurring storytelling" (13-14). In the work of Page and Georgakopoulou, Facebook storytelling is, indeed, treated as "naturally occurring," as a "natural" expansion of the spontaneous, unsolicited storytelling (cf. Sacks) that takes place in face-to-face interaction. 
So, in what sense is a Facebook status update a narrative? The simple answer is that it is always a narrative in the natural narratology sense. Yet online storytelling is gradually changing our notion of the "naturally occurring." Let us consider my colleague Jarkko Toikkanen's ${ }^{1}$ status update reporting, in the present tense, that he arrives home - from an unspecified journey - to an empty house. At first glance, it may be not the most ambitious aestheticization of one's life and experience:

(1) Jarkko Toikkanen

23 April at 16:44

Returns home to an empty house. ${ }^{2}$

Out of context, the expression would appear as a mere report on the state of things. Yet it potentially gives rise to speculations about some related, possibly dramatic events before or after this perception of an empty house. It could even hint at some deep psychological undercurrents. Where is he returning from, exactly? Where is Jarkko's family - and especially, where is his wife? Did the emptiness of the home come as a surprise to Jarkko? Why else would he report his experience? Or, in a yet more literary vein, is the "House" a metaphor for Jarkko's mind, self, or identity? The fact that Jarkko's Facebook friends also know that he is a researcher of horror fiction adds an extra dimension to this report. The pull toward an experiential reading comes from Facebook as a narrative environment and especially from the prompt "What's on your mind?"3 - the same question that a psychoanalyst asks an analysand. The stark contrast between the generic expectation of affectivity and the unapologetic bluntness of Jarkko's report create interpretive possibilities for existential angst, even horror. Referentially speaking, all these speculations are absurd. Aesthetically speaking, they illustrate the ironic potential that inheres in the tension between a tellable experience and an inconsequential event, so very typical of Facebook expressivity.

Thus, my first literary-narratologically informed suggestion concerning the expressive and narrative potential of Facebook is that the dominant interpretive frame in reading the status updates is that of "narrativity as mediated experientiality," precisely in the sense theorized by Fludernik (12). As suggested by this theory, "there can . . . be narratives without plot, but there cannot be any 
narratives without a human (anthropomorphic) experiencer of some sort at some narrative level" (Fludernik 13). It is almost as if social media life-storying — the perpetual sharing of "What's on your mind" - were a concretization of Fludernik's theory. I would even claim that simple notifications of, for example, a user's location (an airport, a restaurant), acquire an aura of experientiality when shared on Facebook - there is a "what is it like" quality to these reports that results solely from the experiential expectancy created by the platform.

Moreover, the prominence of the experiential frame may encourage an updater to experiment with the content. What are the limits to internalizing uninteresting reports of the everyday? What does it mean to have something "on your mind" (cf. Mäkelä 2013b: 141)? In addition to Fludernik, David Herman (2009, 143-153) also emphasizes qualia - the subjective quality of experience, the "what is it like" — as the driving force of narrativity. The Facebook prompt question functions as a test of the prevalence of narrativity as a cognitive frame: one can enter anything in the "What's on your mind?" field, and it will be read experientially. In fact, even Herman's own example of a merely “quasi-narrative description," the Little Piggy nursery rhyme (2009: 13), would be a typical instance of experiential life-storying on Facebook, activating a sense of qualia in the reader: "This little piggy went to market. . . This little piggy stayed home.” Many of my Facebook friends make an art of exactly such "Little Piggy" status updates and the experiential, expressive aura they acquire within this genre.

Consequently, if we take the cognitive-narratological definition of narrativity at face value, we should concentrate precisely on the narrativity of singular updates instead of crafting coherent life stories from the reverse diachrony of a person's entire Facebook wall (cf. Page 2010: 441; Georgakopoulou 2017: 3536). Small stories research, which has gained ground in sociology and sociolinguistics during the last decade, conforms to the new cognitivenarratological understanding of narrativity as relatively independent from causal sequencing, thus acknowledging the centrality of fragmentary and momentary lifestorying for our social existence (e.g., Georgakopoulou 2013: 206-207). Along with the notion of narrativity as a scalar phenomenon and a cognitive schema, instead of a fixed category of texts, there comes the possibility of manipulating the reader's conception of what counts as a narrative. Georgakopoulou and other sociolinguists do not take up the possibility of skillful manipulation, although they pay abundant 
attention to the challenge that small stories or "storytelling on the go" pose to traditional Labovian criteria of tellability and temporal (reflective) distance. Yet much of the literary potential of Facebook hinges precisely on the platform's "weak narrativity" (McHale 2001, Tammi 2006), i.e., in the sense that it does not rest on coherent, causal sequencing of tellable events.

A notable difference between a "naturally occurring" narrative as defined by Labov and a spontaneous, ostensibly unreflected social media update is that the latter lacks evaluation, the after-the-fact narratorial reflection on the emotional and moral significance of the told. Page (2012: 72-86) suggests that generally affective discourse in updates (such as interjections and intensifiers) is equivalent to the evaluative stage in oral storytelling. Page, Harper, and Frobenius (199) also mention "likes" as an interactive form of evaluation; Georgakopoulou, when analysing "storytelling on the go" in face-to-face communication, maintains that both the evaluation and the "what it is like" of small stories are co-constructed in the spontaneous social exchange between the teller and her audience (2013: 208, 215-19). A "literary" reading, however, provides a contrasting, non-social point of view on the apparently eventless and unreflected reports on Facebook. In literary fiction, qualia are conventionally located in consciousness representation - that is, in literary forms of the solitary, non-communicative language of (constructed) interiority. If read as literary communication, prosaic Facebook updates turn into immediate expressions of inwardness.

Let us look at another, more substantial and explicitly metareflective status update:

(2) Anonymous

31 January at 11:05

Just wondering how to come up with a really annoying update. There's nothing about the kids that I could brag about right now. The man dozed off again and isn't even here on Facebook so that I could confess my love to him, and otherwise there's of course no point. Haven't been able to get dressed myself, don't feel like cooking, the activity tracker shows hardly any steps. It seems I'm just listing stuff to fill the feed with nothing important, it's just that these fingers don't stop and since I have this attention whoring disorder you know. 
This updater communicates honesty and authenticity through meta-narrative strategies, highlighting the fact that Facebook, celebrated primarily for its ability to bring people together, can also be interpreted as the emblem of a meaningless, event-less, lonely, and drifting life. As such, it is the perfect platform for thematizing and aestheticizing the ambiguous relationship between event, experience, and narration. This is the darker, existentially experiential "what it's like" side of Facebook narration, overlooked by sociolinguistic approaches that always foreground social networking and co-construction. This contemporary condition of a networked individual is encapsulated in the motif of the "activity tracker" in the quoted update: is Facebook not an interactive version of the activity tracker itself, demanding constant reporting on our active existence, and as such, creating existential angst?

Yet aesthetically rewarding interpretative frames can be imported from literary fiction to cope with this experiential vicious cycle. For example, the status update of the anonymous attention seeker could have been posted by Emma Bovary, the emblem of modern ennui to which Flaubert gave formal expression in the iterative narration of the same mental states:

One after another, along they [the days] came, always the same, neverending, bringing nothing. Other people's lives, however drab they might be, were at least subject to chance. A single incident could bring about endless twists of fate, and the scene would shift. But, in her life, nothing was going to happen. Such was the will of God! The future was a dark corridor, and at the far end the door was bolted. . . .

— I've read everything, she said to herself.

And she sat there playing with the fire-irons, or watching the rain falling. (Flaubert 49)

Here Emma's experiential voice verges on the narrator's voice and forms different kinds of constellations that can be roughly named free indirect discourse. The text also stages the typical scene for a modern figural voice to emerge, marked by uneventfulness, boredom, loneliness, and the inability to make one's experience meaningful. If we think of a typical social media updater, these existential facets of 
life are not what people usually wish to share (quite the contrary, the amazing eventfulness of our lives and the meaningfulness of our experiences is what we typically like to convey). Yet, intentionally or unintentionally, some updaters foreground these existential concerns of a modern individual through their social media voice.

In such a use, a status update foregrounds the physical loneliness and seclusion of the updater ("Haven't been able to get dressed myself"), instead of possibilities for networking. In literary terms, the updater's description of "what it is like" can be interpreted to turn into a mind's stage (cf. Fludernik 153-59), just as concretely as in dramatic monologues or arias in the theater. The protagonist apparently "forgets" the presence of an audience, and communicative utterances begin to construct non-communicative interiority. An artistic parallel can be found in the epistolary tradition, where the letter writer's discourse, when reaching its emotional peak, often turns inwards and gives rise to what Janet Gurkin Altman (57-59) has labeled the "eclipse of the confidant." This interpretation finds support in the notion of collapsed contexts (Wesch; Marwick and boyd) which is used by researchers of social media to characterize the heterogeneity of the audience and the incongruity of communicative contexts between different users. The social media updater writes for so many diverse audiences - colleagues, former schoolmates, distant relatives - without the support of a shared physical or institutional setting, that some sort of an "eclipse of the confidant" is inevitable. Paradoxically, the more Facebook friends one has, the more it may feel like speaking into a void. In the $17^{\text {th }}$ and $18^{\text {th }}$ centuries, epistolary communication was appropriated by the emerging fictional techniques for representing consciousness - providing, as Samuel Richardson famously writes in "Hints of Prefaces for Clarissa", "the only natural Opportunity ... of representing with any Grace those lively and delicate Impressions which Things present are known to make upon the Minds of those affected by them" (Richardson 6). An internalizing reading of Facebook experientiality may lead us to ask whether contemporary social media are providing us with new narrative frames of interiority. As exemplified by the status update (2), this is a paradoxical narrative frame in terms of communication: seemingly unedited interiority and non-reportability coupled with context collapse and a craving for attention. 
There is yet another communicative aspect reminiscent of literary representations of consciousness, an aspect related to the collapsed contexts of social media and contrasting with the parameters of "naturally occurring" face-toface storytelling: intensified textual experientiality resulting from the absence of the body (see, e.g., Panger). Social media updaters need to "write themselves into being" (boyd 119). In the absence of a revealing emoticon or selfie, the experientiality of a status update remains artfully ambivalent. Imagine Jarkko Toikkanen using a smiley face or a crying face — or a selfie — with his update "returns home to an empty house." The status update is considerably more effective experientially and triggers much more interesting interpretations as a mere textual voice, exactly as we encounter the experience of many literary characters in streamof-consciousness or free indirect discourse. My hypothesis is that many updaters, including Toikkanen, half-intentionally activate this analogy to a literary voice of figural experience by referring to themselves in the third person. Third-person (that is, heterodiegetic) narration is also a remnant of a previous version of Facebook where the status prompt actually began with the person's name and invited the use of the third person more directly.

Referring to oneself in the third person on Facebook opens up possibilities for intentional or unintentional experiential ambiguity. In the framework of my aestheticizing reading, we can assume that if Jarkko had written "I returned home to an empty house," the update would not have been as psychologically laden as it is with its third-person reference. The use of the third person in Jarkko's update figuralizes and internalizes the narrative situation, resulting in a report that simulates a penetrating, unnatural point of view on the updater's own, apparently non-verbalized experience. The third person converts a dialogical relationship into a potentially non-communicative language. The updater seems to turn into a character and an omniscient literary narrator at the same time, thus downplaying the fact that we still share a first-person experience of actual events. The third person used destabilizes the source of the report and thus leaves room for asking what Jarkko knows or does not know and what the level of reflection is with regard to his actions or experience (see, e.g., Cohn 1978: 46-57). As Dorrit Cohn notes in her influential study on literary consciousness, representation, an internally focalized description of events "link[s] psyche and scene" (ibid. 49). 
On Facebook, the experiential frame produced by the status prompt question and the estranging third-person reference, together create a narrative situation that closely resembles internal focalization. This observation at least seemingly challenges my own previous notions of the peculiar "unnaturalness" of figural voice in fictional consciousness representation, a stance that David Herman (2011) criticizes together with other non-universalist theories of fictional minds under the rubric of the "Exceptionality Thesis." Indeed, this resemblance between literary and non-literary frames of interpretation suggested by my Facebook reading supports Herman's critique of the Exceptionality Thesis and the contrasting claim he makes for the universality of readerly frames in interpreting minds and experiences encountered inside and outside of fiction. As Herman notes, "the procedures used to engage with the minds evoked in fictional narratives necessarily piggyback on those used to interpret minds encountered in other contexts (and vice versa)" (2011: 10). What happens in my Facebook reading is precisely this "vice versa" (for exactly the same point with the same quotation, see Hatavara and Mildorf 68), a traffic of interpretive frames from fictional to non-fictional narrative context. This is the other side of the cognitive universality claim, often ignored by cognitive narratologists who wish to test "real mind discourses" (Palmer 16), but recently probed by myself in the context of reality television (2015) and by Mari Hatavara and Jarmila Mildorf with an interview and a museum exhibition as their material.

Yet I would still hold on to the Exceptionality Thesis, not in the sense of categorical difference, but in the sense of difference in foregrounding (see also Mäkelä 2013b: 139; 2015: 253). In my previous work, I repeatedly argued that specific compositional aspects of literary conventions highlight facets of human experientiality. The same can be said of Facebook experientiality. Facebook status updates have a compositional capacity to highlight very specific aspects of human experientiality. The narrative affordances of Facebook that I consider most formative in the shaping of Facebook experientiality are simultaneity and tellability, features that are also highlighted by the quoted exemplary status updates by Toikkanen and by the anonymous "attention seeker." "Simultaneity" refers roughly to what sociolinguists point to as the "breaking news" quality of the small stories, but I will attempt to provide some added literary-narratological value to the analysis of social media by invoking theories of present-tense narrative fiction and some interpretative assumptions related to them. 
Tellability is one of the key variables in narrative communication, first studied in the Labovian sociolinguistic tradition and later juxtaposed with the literary-narratological notions of narrativity (e.g. Hühn). In my literary analysis, tellability not only marks the expressive limits of a Facebook status update but is also a parameter whose manipulation forms a central part of Facebook life-storying as a narrative craft. I will borrow the ethos of literary narratology and some of its theoretical formulations in order to focus on the creative and ambivalent use of simultaneity and tellability in Facebook status updates, yet my aim is to show that these strategies foreground experiential qualities that are, in the end, not reducible to literary effects.

\section{Simultaneity}

The strong expectancy of experientiality in Facebook status updates relates closely to the ideal of immediacy. The anonymous "attention seeker" in example (2) explicitly thematizes simultaneity as one of the defining textual features of Facebook storytelling: "Just wondering how to come up with a really annoying update. There's nothing about the kids that I could brag about right now. . . . It seems I'm just listing stuff to fill the feed with nothing important, it's just that these fingers don't stop" (my italics). The update displays several typical linguistic features of Facebook expressivity analyzed in sociolinguistic research such as the pronounced use of temporal adverbials that stress immediacy (Page 2012: 101104). The update also thematizes the disembodiment of social media communication by mentioning the fingers that "don't stop." Yet the post is also a metanarrative reflection on the social, expressive, and experiential nature of "breaking news" stories, the dominant genre on social media. In the sociolinguistic paradigm, simultaneous narration on Facebook or Twitter has been primarily celebrated for its many social networking affordances. Georgakopoulou, for example, highlights multiple tellership and co-construction as one of the most pertinent features of "breaking news"; she even concludes that the qualia, the "what's it like" of the teller, are "co-constructed with the interlocutors" (2013: 208).

Simultaneous narration and experiential immediacy may, however, create interpretive effects that have less to do with interpersonal connectivity and more with one's inability to connect - even with oneself. In Jarkko's coming home "to an empty house," the present tense enhances not so much social sharing but 
existential uncertainty and lack of contextual and psychological framing. The reader of the update is suspended on the threshold of Jarkko's house, not knowing where one was coming from nor where one is going. No mundane explanation, either in the comments section or in the ensuing face-to-face communication, will completely resolve this suspension.

As demonstrated by Per Krogh Hansen in his analysis of first-person present-tense narration in contemporary fiction, the present tense can be both intensifying and monotonous, often paradoxically both at the same time. Hansen distinguishes a "disturbing apathetic sense" (329) in some contemporary firstperson present-tense narratives, implying the protagonist-narrator's inability to make his moment-to-moment experiences meaningful. Conversely, Theo Damsteegt reads present tense narratives as highlighting heightened self-awareness and emotional intensity on the part of the experiencing-I. This paradox, an inexhaustible nexus upon which to tie the question of narrativity in life and experience, characterizes also Facebook as a narrative platform, not least because the online parameters for sharing experience are gradually transforming our off-line experience as well. How to mediate the immediate? Facebook Live's built-in screen-sharing function has, in a way, solved this narrative-existential problem, but it is still rarely used by my Facebook friends. Instead, updaters experiment with the very impossibility of living and writing at the same time - like Richardson's Pamela and Clarissa and other $18^{\text {th }}$-century epistolary heroines, still holding their pens and reporting terror while their molester is already at the door.

As Hansen notes, present-tense fiction challenges what is conventionally considered one of the minimum conditions of narrativity, the temporal and spatial distance between narration and the narrated events (317-18). Unsurprisingly, Georgakopoulou characterizes the deviance of "small stories" from the sociolinguistic prototype in much the same terms (e.g., 2017: 37). On Facebook, the narrating-I and the experiencing-I coalesce, resulting in linguistic forms and interpretative effects, and even existential themes, that have a tradition of their own in modern present-tense fiction.

Contemporary present-tense novels such as J. M. Coetzee's Disgrace (2000), or Michael Cunningham's By Nightfall (2010) blur the boundary between first- and third-person narration, thus wrestling with narrative-philosophical problems such as intentionality and immediacy (Mäkelä 2017; see also Cohn 1999: 97). For example, 
in By Nightfall, the protagonist, who seems to be the ironically distancing narrative voice reporting on himself in the third person, wants "to be a wheeler and dealer (as some would call him), a denizen of the present, though he can't quite live in the present; he can't stop himself from mourning some lost world, he couldn't say which world exactly but someplace that isn't this" (22). Some parts of the novel could easily be remediated into tragically ironic, self-contained status updates, e.g., "Peter Harris, hostile child, horrible adolescent, winner of various second prizes, has arrived at this ordinary moment, connected, engaged, loved, his wife's breath warm on his neck, going home" (13). However, in the context of the whole novel, any attempt at an aesthetic or otherwise comprehensive framing of a "pregnant moment" is doomed to fail, and this is of course one of the leitmotifs of the modernist novel dealing with identity and the temporality of existence. The heavy weight of the modernist tradition looms large also in Toikkanen's homecoming report, not primarily because of the updater's artistic intentions but because the platform invites the paradox of mediated immediacy, the artful framing of the present. The effects of intensity marking narrative self-consciousness, as well as monotonousness marking the lack of self-consciousness, are always already inscribed in the textual and narrative parameters of a status update.

As in the epistolary tradition, immediacy and "inwardness" in social media can be the result of a careful design. In early modern times an essential part of the craft of letter writing was to convey and, indeed, construct the sense of an unmediated emotional flux. The governing artistic principle in many epistolary novels was that it is precisely writing that dictates the events, emotions, and experiences and not the other way around. A good example is Valmont's textual method for creating a seemingly authentic emotional upheaval in Les Liaisons dangereuses (1782):

I took great pains with my letter and attempted to reproduce in it that disorder which alone can portray feeling. I was, at all events, as unreasonable as I was capable of being: for there is no showing tenderness without talking nonsense. It is for this reason, it seems to me, that women are better writers of love-letters than men. (150) 
The aim of many Facebook status updates seems to be precisely the same - to appear unedited, unreflected, genuine expressions of existence, and particularly, of emotion. Leaving out capital letters and punctuation, and not correcting typos all serve this expressive function. Seen from a literary-artistic angle, there is, indeed, a remarkable affinity between the epistolary tradition, with its focus on the experience of the writer, and the breaking-news stories shared on social media. A particularly illustrative example is the updater in (2) who is simultaneously conscious of her audience ("Just wondering how to come up with a really annoying update. ... It seems I'm just listing stuff to fill the feed") and meta-narratively and self-reflectively embedding the narrative act within her own, secluded, bodily parameters of writing (“Haven't been able to get dressed myself . . . it's just that these fingers don't stop").

We are approaching the dark side of Facebook experientiality, where present tense narration assumes an existentialist function. My next example presents a subtle variation of heightened self-consciousness and apathetic monotonousness that I find to be the specific source of common narrative creativity on Facebook. I have reversed the order of the following series of updates, posted within two days, into a chronology of (non-)events. This example demonstrates that "breaking news" on social media do not exclusively serve such connecting and co-constructing functions as foregrounded by the sociolinguistic researchers of small stories.

(3) Anonymous

[Yesterday at 9:05]

Gah. Monday. Coffee!

[Yesterday at 10:27]

So also this week started steep downhill. Down down down we go.

Swoooohs. Hope there's no one standing on the opposite slope.

[Yesterday at 12:08]

Oh well, gotta teach I guess, though I'd rather say vsjo ravno and hit the hay. Screw this. 
[Yesterday at 13:53]

And just when I thought the week can't get any worse $: ;$ [link to news]

"Matula retired - 30 years of $A$ Case for two was enough"

[Yesterday at 15:45]

Again, one day less on the journey to untimely demise.

[12 hours ago]

caught the flu yesterday evening - for the second time this autumn $: 2$ That's it then, and just when the teaching rate is getting the most feverish.

[7 hours ago]

My office hour just started. Now you can be sure that no one's going to disturb you and you can focus on the essentials.

[6 hours ago]

ZZZ - he's asleep. Not quite but almost. Soon exercise course; luckily such type that I'll just leave the kids to rehearse and go get myself a cuppa.

[5 hours ago]

Is luckily not alone with his hardships: [person Y] has also spent his day lamenting the toilet paper whose layers don't meet.

[two hours ago]

Crazy world.

[about an hour ago]

*Sniff*

The series of mundane "breaking news" develops into a professional satire of a university lecturer who numb-mindedly prefers to mind his own business. Loneliness and seclusion are foregrounded, paradoxically, by the frequency of the posts. While expressly dealing with the meaninglessness of life, the series nevertheless weaves a poetic net of interrelations and motives, mostly having to do 
with coffee drinking and catching a cold ("just when the teaching rate is getting the most feverish"). From a narratological perspective, the most striking detail is "ZZZ - he's asleep," as it recycles the canonical example highlighting the "unnaturalness" of present tense narration, one that appears even in the title of Dorrit Cohn's essay "I Doze and Wake: The Deviance of Simultaneous Narration" (1999: 96-108). For Cohn, simultaneous narration, a true manifestation of the synchrony of language and event, is one of the "signposts of fictionality," a narrative situation that radically departs from naturally occurring and non-fictional storytelling. This literalization of simultaneous narration in the narratological scholarship leads one easily to literalize the "breaking news" of social media, albeit distinctively in cases of self-storying this interpretative framing resulting not only from linguistic modes but also from modernist-existentialist themes.

Next I turn to a narrative feature of Facebook whose artful use bases itself on a negotiation not with literary, but everyday face-to-face storytelling conventions.

\section{Tellability}

It would not be completely impossible to imagine Toikkanen's homecoming (1), the stagnant weekend impressions in example (2), or the series of updates by a university lecturer in (3) being shared in face-to-face conversations, but it is unlikely that the teller would actually "take the floor" as a storyteller with these narratives. Yet on Facebook, the updaters dedicate a whole post to these reports, without any evaluation or other explicit justification. Page justifies the low tellability of status updates by the context collapse, the difficulty of mediating between different audiences: "The low tellability typically found in small stories might be interpreted as a social strategy that enables writers to connect with their Friends online, but also mitigates the threat of undesirable levels of self disclosure in a networked public ... the tellability of the story must be sufficiently low as to avoid unwanted personal disclosure, but in terms of rhetorical style, tellability must be high enough to gain and maintain the attention of the audience" (2012:86).

Elinor Ochs and Lisa Capps maintain that stories with low tellability are "geared less to narrative as performance and more to narrative as a social forum for discovering what transpired" (38). My examples, chosen with literature in mind, suggest, however, just the opposite: low tellability may be used to foreground 
narrative as a performance. This is reminiscent of the two possible foci in the definition of tellability, noted, for example, in Raphaël Baroni's entry on "Tellability" in The Living Handbook of Narratology: "At issue is the breaching of a canonical development that tends to transform a mere incident into a tellable event. However, tellability may also rely on discourse features, i.e. on the way in which a sequence of incidents is rendered in a narrative." Facebook status updates make for an excellent platform for experimenting with tellability by probing its limits; this narrative practice renders tellable the very effort of telling an insignificant or, conversely, a too intimate experience.

In the study of social media storytelling, less attention has been paid to what Neil S. Norrick has labeled the "dark side of tellability" (see, however, Thomas 2017: 365). Norrick's definition resonates strongly with some of the storytelling limits and affordances resulting from the collapsed contexts of social media:

[W]e need a two-sided notion of tellability: Some events bear too little significance (for this teller, this setting, these listeners) to reach the lowerbounding threshold of tellability, while others are so intimate (so frightening) that they lie outside the range of the tellable in the current context. . . . Even safe and impersonal stories do much work in social identity construction, by demonstrating recognition of and respect for standard group norms, but dangerous ones, by pushing boundaries, accomplish a different kind of identity work, due to the higher risk factor. (2005: 328)

Like the essential tension between self-consciousness and numbness or monotonousness in simultaneous self-storying, the negotiation between very low and very high tellability is readily apparent in reports on one's own life events and experiences on Facebook. This platform-specific communicative tension would explain my menacing interpretation of Jarkko Toikkanen's homecoming; extremely low tellability may open up a venue for extremely high tellability. Page remarks that expressivity and affectivity enhance the tellability of "small stories" on social media (2012: 72, 85-86), but I would suggest that the mere experiential framing in the "what's on your mind" prompt lends an aura of tellability and internalized eventfulness to any reported fragment of life. 
Yet there are updates that negotiate the "upper limit" of tellability, verging on the too intimate or dramatic revelations of one's personal life, e.g.:

(4) Anonymous

28 November 2017

Can't stand it. Everything is fucking falling apart at once.

This status update is a representative example of a small story type that Georgakopoulou describes using the concept of "narrative stancetaking," that is, "the moment of teller agency, when the teller chooses to signal a narrative tale or telling even if one does not, indeed, follow" $(2017,39)$. The post, hinting at some painful events in the updater's life, clearly expresses "a need (to begin) to tell a story, even in situations which constrain full tellings"; it "evokes narrativebiographical claims about how narrative meaning-making offers a privileged entry into subjectivity" (Georgakopoulou 2017: 40). Yet in contrast to the cases of narrative stance-taking analysed by Georgakopouolou where Facebook friends are prompted to ask specifying questions (“Oh my God! Are you OK?”, ibid. 43), here the update is primarily about drawing the limit of tellability — the events hinted at are clearly on the dark side of tellability. This interpretation is confirmed by the comments posted under this status update, as none of them is interrogative. ${ }^{4}$ The interlocutors' comments seem to draw a tangible line between the tellable and the untellable, consisting of simple expressions of sympathy, while at the same time, the updater herself is "taking a narrative stance."

Again, we can see that a narrative strategy, embraced as a narrative networking device in sociolinguistic studies, can also serve a "darkly existential" narrative function, precisely because it falls short — is meant to fall short - in interpersonal terms. These dimensions of storytelling are barely translatable to other narrative environments; they feed on the very limits of their own medium. For Georgakopoulou, however, the ability to share breaking news about one's own life on social media results in further opportunities for sharing: "Tellability has long been associated in narrative analysis with reporting the extraordinary and with world-disruption. But in the case of breaking news, the recency of events becomes storytelling currency and tellability becomes the ability to tell. Subsequently, tellable stories become circulatable stories and untold (untellable) stories as 
uncirculated (uncirculat-able) stories" (2013: 221). Yet it is difficult to imagine Toikkanen's reporting his return "to an empty house" in any other context with such a clear gesture of "taking the floor," or the attention-seeker of our example (2) to continue the story about her uneventful Sunday morning at her workplace on Monday, with additional details and further reflection on her need for attention. In this sense, the examples I have discussed do not fit into Georgakopouolou's definition of a "small story," as one of her criteria is the "the portability of the stories in different environments (e.g., from online to offline and vice versa)" (2013: 202). Instead, the analysed status updates reflect, each in its own way, the problematic relations between event, experience and meaning as framed by a particular platform.

Thus life-story discourses in social media represent a theoretically fertile middle ground between artistic intentionality and spontaneous narrativization. The analyzed narrative strategies cultivate what Jean Burgess has defined as "vernacular creativity, ... a productive articulation of consumer practices and knowledge (of, say, television genre codes) with older popular traditions and communicative practices (storytelling, family photography, scrapbooking, collecting)" (207). I have attempted to demonstrate how some literary traditions of self-expression and representation of interiority live on and transform into new, textually and compositionally determined narrative practices, and how this takes place even in the most mundane and casual status updates. A quasi-literary reading of Facebook voices reveals their textual-narrative potential: social media provides us with an inexhaustible platform for the configurations of tellability, intentionality, expressivity, temporal experience, and the textualization of the mind. Yet the danger of reading too much intention into an everyday practice looms large for a literary narratologist; in fact, Burgess warns against the elitism that may result from treating media practices as "texts" and as "allegorical emblems of the critic's own activity” (209; here Burgess is rephrasing Meaghan Morris's 1990 essay “Banality in Cultural Studies"; see also Thomas 2017: 363). My selection of examples posts by literary or linguistic professionals, is, admittedly, reflective of such elitism. Yet in the same spirit as I have argued elsewhere for the existence of "unnaturalizing" reading tendencies as a counterforce to cognitive apperception (see, esp., Mäkelä 2013), I maintain that these savvy life-writers only highlight and 
thematize elementary features of this platform whose creative use does not require a particularly literary mindset. Nor is a literary mindset required for an aesthetic appreciation of such an experimental use, yet both narratology and social linguistics are needed for theorizing and analysing it.

While cultural studies scholars express their concern with methods that treat practices as texts, literary scholars are increasingly likely to agonize over the paradigm shift where narrative fiction gets abandoned as an object of study in favour of storytelling in everyday media environments. For example, Werner Wolf writes: "the question arises of whether abandoning literature as the original home domain of narratology does not bespeak literature's loss of status as a whole" (157). Wolf continues to voice his doubts regarding the ability of literary narratologists to appreciate the distinctiveness of the medium that is, methodologically speaking, "new" to them: "they enter territories in which they are not at home and where they may be likely to erroneously overstress similarities" (ibid.).

Yet my argument for a literary Facebook narratology rests on the assumption that a disciplined reading of fiction can make one a perceptive and innovative reader of online storytelling, particularly as regards its experimentation with the textual affordances of the medium. Furthermore, a comparison between literary techniques and everyday social media updates sheds light on the uses and effects of both these narrative environments, the intentionally artistic sphere of literature and the intentionally experiential sphere of social media, all the more so since contemporary literary practices are increasingly absorbing influences from the new media. The type of expressive and narrative self-reflexivity in the use of social media that my examples have demonstrated is likely to be a transient phenomenon, one that my daughters' generation will not recognize. Maybe they will have no reason to reflect on whether their everyday life is worth reporting; perhaps they will see no tension between living and sharing online. Yet I do think that this peculiar phase of textuality in our lives, when we are not sure what to do with social media and whether it should form an integral part of our lives, will continue to echo in narrative practices, literary and otherwise, and especially in the ways textual minds, voices, and experientiality are constructed.

In sum, the contribution of an originally literary narratology to the study of convergent media and the promotion of media literacy (Jenkins 2006) should be, at least, (1) to import the text-analytical finesse into the analysis of experientiality, 
expressivity, and narrativity in new media; and (2) to pay heed to the multiple ways that culturally established and bifurcated narrative forms and strategies, as well as related themes and topics, travel and modulate in the hands of artful storytellers experimenting with emerging and newly dominant practices.

\section{Works Cited}

Altman, Janet Gurkin. 1982. Epistolarity: Approaches to a Form. Columbus: Ohio State University Press.

Bamberg, Michael \& Alexandra Georgakopoulou. 2008. "Small Stories as a New Perspective in Narrative and Identity Analysis.” Text \& Talk 28:3, 377-396.

Baroni, Raphaël. 2011. “Tellability.” The Living Handbook of Narratology. http://www.lhn.uni-hamburg.de/article/tellability (23 September 2018)

Beckett, Samuel. 1959. Three Novels: Molloy, Malone Dies, The Unnamable. New York: Grove.

boyd, danah. 2001. Taken out of Context: American Teen Sociality in Networked Publics. PhD Thesis in Information Management and Systems. Berkeley: University of California. https://papers.ssrn.com/sol3/papers.cfm?abstract id=1344756 (3 March 2018)(

Burgess, Jean. "Hearing Ordinary Voices: Cultural Studies, Vernacular Creativity and Digital Storytelling." Continuum: Journal of Media \& Cultural Studies 20/2: 201-14.

Cinque, Toija. 2015. Changing Media Landscapes: Visual Networking. Oxford: Oxford University Press.

Cohn, Dorrit. 1978. Transparent Minds: Narrative Modes for Presenting Consciousness in Fiction. Princeton: Princeton University Press. 1999. The Distinction of Fiction. Baltimore: The Johns Hopkins University Press.

Contzen, Eva von. 2018. "Experience, Affect, and Literary Lists." Partial Answers $16 / 2,315-327$.

Culler, Jonathan. 1975. Structuralist Poetics: Structuralism, Linguistics and the Study of Literature. London: Routledge and Kegan Paul.

Cunningham, Michael. By Nightfall. New York: Picador, 2011. 
Damsteegt, Theo. 2005. "The Present Tense and Internal Focalization of Awareness." Poetics Today 26/1: 39-78.

Flaubert, Gustave. 2003. Madame Bovary. Translated by Geoffrey Wall. London: Penguin.

Fludernik, Monika. 1996. Towards a 'Natural' Narratology. London: Routledge. Georgakopoulou, Alexandra. 2007. Small Stories, Interaction and Identities.

Amsterdam: John Benjamins. 2013. "Storytelling on the Go: Breaking News as a Travelling Narrative Genre." In The Travelling Concepts of Narrative, ed. Mari Hatavara, LarsChrister Hydén, and Matti Hyvärinen. Amsterdam: John Benjamins, pp. 201-24.

---------. 2017. "Narrative/Life of the Moment: From Telling a Story to Taking a Narrative Stance." In Life and Narrative: The Risks and Responsibilities of Storying Experience, ed. Brian Schiff, A. Elizabeth McKim, and Sylvie Patron. Oxford: Oxford University Press, pp. 29-54.

Greenberg, Clement. 1940. “Towards a Newer Laocoön.” Partisan Review 7, 296310.

Hallet, Wolfgang. 2014. "The Rise of the Multimodal Novel: Generic Change and its Narratological Implications." In Storyworlds across Media: Toward a Media-Conscious Narratology, ed. Marie-Laure Ryan and Jan-Noël Thon. Lincoln: University of Nebraska Press, pp. 151-72.

Hansen, Per Krogh. 2008. "First Person, Present Tense: Authorial Presence and Unreliable Narration in Simultaneous Narration." In Narrative Unreliability in the Twenty-First Century First-Person Novel, ed. Elke D'hoker and Gunther Martens. Berlin: De Gruyter, pp. 317-38.

Hatavara, Mari, and Jarmila Mildorf. 2017. "Hybrid Fictionality and Vicarious Narrative Experience." Narrative 25/1: 65-82.

Herman, David. 2009. Basic Elements of Narrative. Oxford: Wiley-Blackwell. -. 2011. "Introduction." In The Emergence of Mind: Representations of Consciousness in Narrative Discourse in English, ed. David Herman. Lincoln: University of Nebraska Press, pp. 1-40.

Hühn, Peter. 2008. "Functions and Forms of Eventfulness in Narrative Fiction." In Theorizing Narrativity, ed. John Pier and José Angel García Landa. Berlin: De Gruyter, pp. 141-64. 
Jenkins, Henry. 2006. Convergence: Where Old and New Media Collide. New York: New York University Press.

Labov, William. 1972. Language in the Inner City. Studies in the Black English Vernacular. Philadelphia: University of Pennsylvania Press.

Laclos, Choderlos de. 1961 [1782]. Les Liaisons dangereuses. Translated by P. W. K. Stone. London: Penguin.

Levine, Caroline. 2015. Forms. Whole, Rhythm, Hierarchy, Network. Princeton: Princeton University Press.

Mäkelä, Maria. 2011. "Masters of Interiority: Figural Voices as Discursive Appropriators and as Loopholes in Narrative Communication.” In Strange Voices in Narrative Fiction, ed. Per Krogh Hansen, Stefan Iversen, Henrik Skov Nielsen, and Rolf Reitan. Berlin: De Gruyter, pp. 191-218. -. 2013a. "Realism and the Unnatural." In A Poetics of Unnatural Narratology, ed. Jan Alber, Henrik Skov Nielsen, Brian Richardson. Columbus: Ohio State University Press, pp. 142-66. -. 2013b. "Cycles of Narrative Necessity: Suspect Tellers and the Textuality of Fictional Minds." In Stories and Minds: Cognitive Approaches to Literary Narrative, ed. Lars Bernaerts, Dirk De Geest, Luc Herman, and Bart Vervaeck. Lincoln: University of Nebraska Press, pp. 129-51. 2015. "Mind as World in the Reality Game Show Survivor." In Narrative Theory, Literature, and New Media: Narrative Minds and Virtual Worlds, ed. Mari Hatavara, Matti Hyvärinen, Maria Mäkelä, Frans Mäyrä. London: Routledge, pp. 240-55.

- 2016. "Narratology and Taxonomy: A Response to Brian Richardson." Style 50/ 4: 462-67.

---------. 2017. “The Gnomic Space: Authorial Ethos between Voices in Michael Cunningham's By Nightfall." Narrative 25/1: 113-37.

Mäkelä, Maria, and Merja Polvinen. 2018. "Narration and Focalization: A Cognitivist and an Unnaturalist, Made Strange." Poetics Today 39:3, Marwick, Alice E. and danah boyd. 2010. "I Tweet Honestly, I Tweet Passionately: Twitter User, Context Collapse, and the Imagined Audience.” New Media Society 20/10: 1-20.

McHale, Brian. 2001. "Weak Narrativity: The Case of Avant-Garde Poetry." Narrative 9/2: 161-67. 
McKeon, Michael. 1997. "Prose Fiction: Great Britain.” In The Cambridge History of Literary Criticism: Vol IV, The Eighteenth Century, ed. Hugh Barr Nisbet amd Claude Rawson. Cambridge: Cambridge University Press, 238-63.

Norrick, Neal R. 2005. “The Dark Side of Tellability.” Narrative Inquiry 15/2: $323-43$.

Ochs, Elinor, and Lisa Capps. 2001. Living Narrative: Creating Lives in Everyday Storytelling. Cambridge, MA: Harvard University Press.

Page, Ruth. 2010. "Re-Examining Narrativity: Small Stories in Status Updates." Text\&Talk 30/4: 423-44.

-. 2012. Stories and Social Media: Identities and Interaction. London: Routledge.

----------. 2015. “The Narrative Dimensions of Social Media Storytelling: Options for Linearity and Tellership." In The Blackwell Handbook for Narrative Analysis, ed. Anna de Fina and Alexandra Georgakopoulou. Oxford: Blackwell, pp. 329-48.

Page, Ruth; Richard Harper, and Maximiliane Frobenius. 2013. "From Small Stories to Networked Narrative: The Evolution of Personal Narratives in Facebook Status Updates." Critical Inquiry 23/1: 192-213.

Palmer, Alan. 2004. Fictional Minds. Lincoln: University of Nebraska Press.

Panger, Galen Thomas. 2017. Emotion in Social Media. PhD dissertation in Information Management and Systems. Berkeley: University of California. http://people.ischool.berkeley.edu/ gpanger/dissertation/emotion_in_social_ media.pdf (17 January 2018)

Richardson, Samuel. 1964. "Hints of Prefaces for Clarissa." In Samuel Richardson, Clarissa: Preface, Hints of Prefaces, and Postscript. Ed. R.F. Brissenden. The Augustan Reprint Society 103. Los Angeles: William Andrews Clark Memorial Library, pp. 1-14.

Sacks, Harvey. 1992. Lectures on Conversation. Ed. G. Jeffersson. Oxford: Basil Blackwell.

Tammi, Pekka. 2006. “Against Narrative.” Partial Answers 4/2: 19-40.

Thomas, Bronwen. 2013. "140 Characters in Search of a Story: Twitter Fiction as an Emerging Narrative Form.” In Analysing Digital Fiction, ed. Alice Bell, Astrid Ensslin, and Hans Kristian Rustad. London: Routledge, pp. 94- 108. 
2016. "Tales from the Timeline. Experiments with Narrative on Twitter.

Comparative Critical Studies 13/3: 353-69.

2017. "Whose Story Is It Anyway? Following Everyday Accounts of

Living with Dementia on Social Media." Style 51/3: 357-73.

Thon, Jan-Noël. 2016. Transmedial Narratology and Contemporary Media Culture.

Lincoln: University of Nebraska Press.

Wesch, Michael. 2009. "YouTube and You: Experiences of Self-Awareness in the Context Collapse of the Recording Webcam." Explorations in Media Technology 8/2: 19-34.

Wolf, Werner. 2011. "Narratology and Media(lity): The Transmedial Expansion of a Literary Discipline and Possible Consequences." In Current Trends in Narratology, ed. Greta Olson. Berlin: De Gruyter, pp. 145-80.

${ }^{1}$ Jarkko is the only updater referred to by his own name in my examples, for the accidental reason that he was present at the same symposium in Aarhus (2016) where I first presented a draft of this paper.

${ }^{2}$ All examples are my translations from Finnish.

${ }^{3}$ This has been the prompt question since 2009. Before that, the status updater was prompted by more action-oriented formulas: "X is ..." and "What are you doing right now?"

${ }^{4}$ Due to the exceptionally personal tone of both the update and the compassionate responses, I refrain from quoting the responses here; there were four comments, all of them expressions of support, not questions, and none referred to any concrete events. 